\title{
Differences in Enzymatic Activities of Cecal Contents of Rats Fed on Differently Processed Dietary Fibers
}

\author{
Chieko Nishizawa, ${ }^{1}$ Takeo OHTA, ${ }^{1,2, *}$ Yukari EgashiRA ${ }^{2}$ and Hiroo SanadA ${ }^{1,2}$ \\ ${ }^{1}$ Division of Production Science and Technology, Graduate School of Science and Technology, ${ }^{2}$ Department of Bioproduction Science, \\ Faculty of Horticulture, Chiba University, 648 Matsudo, Matsudo-shi 271, Japan
}

Received April 24, 1997; Accepted August 30, 1997

\begin{abstract}
Enzymatic activities in cecal contents were studied on rats fed on high cholesterol diets with ferulic acid arabinoxylan ester (FAX) and arabinoxylan (AX); both were processed from refined corn bran (RCB) and were compared with those of cellulose(CE)- and RCB-fed rats. The enzymatic activities in the ceca changed according to the diets. Xylanase activity, arabinofuranosidase activity and ferulic acid esterase activity appeared in the cecum of the FAX- and AX-fed rats, but these activities were not observed in the cecum of CE- and RCB-fed rats. FAX and $\mathrm{AX}$ showed a tendency to decrease serum cholesterol levels. At first, xylanase and arabinofuranosidase were supposed to attack the FAX and AX main chain and side chain, and thus high molecular weight FAX and AX became lower molecular weight fragments. At that time, ferulic acid esterase was presumed to attack and FAX was degraded lower. These enzymes might act synergistically.
\end{abstract}

Keywords: dietary fiber, rat cecum, ferulic acid, enzymatic activity, xylanase activity, arabinofuranosidase activity, ferulic acid esterase activity

There have been many investigations on dietary fiber, and evidence is emerging that dietary fiber has an influence on nutrition because it is fermented, absorbed and has various functions (Ebihara \& Kiriyama, 1990; Ayano,1992). Cereals, such as wheat bran and corn bran, are the main suppliers of dietary fiber. Their structures have been studied in detail (Brillouet et al., 1982; Shibuya, 1984; Kamisaka et al., 1990; Shiba et al., 1992), and it is known that the corn bran cell wall mainly consists of arabinoxylan and that one part of it is esterified with ferulic acid and glucuronic acid (Kato, 1992). Fermented products of dietary fiber by intestinal bacteria, especially short-chain fatty acids, are absorbed and used as a source of energy or physiologically active substances (Chen et al., 1984; Aoe et al., 1988; Ikegami et al, 1995). On the other hand, soluble ferulic acid arabinoxylan ester was obtained by the hydrolysis of refined corn bran (RCB). This compound shows antioxidative activities against autoxidation of linoleic acid and lipid peroxidation of rat liver microsomal system induced by $\mathrm{CCl}_{4}$ (Ohta et al, 1994). When RCB is decomposed by alkali, hemicellulose is liberated and it is known to decrease the serum cholesterol level (Anderson et al., 1979; Nomani et al., 1979; Kirby et al., 1981). In spite of various physiological functions of cereal dietary fiber reported, the mechanisms of these functions, except the mechanism described by the aspects of physical chemistry, have not been studied.

The objective of this study was to compare enzymatic activities in the cecum of rats when the rats were fed different dietary fibers which were obtained from RCB by different processes. We paid attention to the difference in the modification by ferulic acid of dietary fibers. In other words, one

\footnotetext{
*To whom correspondence should be addressed.
}

sample was esterified by ferulic acid and another was not.

\section{Materials and Methods}

Materials Cellulose (CE) was purchased from Oriental Yeast Co., Ltd. (Tokyo) and RCB was kindly presented by Nihon Shokuhin Kako Co., Ltd. (Shizuoka), respectively. All chemicals used in this experiments were of reagent grade.

Preparation of test substances Hydrolysate by acid (ACD) was prepared as shown in Fig. 1. RCB was heated in $30 \mathrm{~mm}$ oxalic acid solution at $121^{\circ} \mathrm{C}$ for $20 \mathrm{~min}$ in an autoclave. After cooling in water, the insoluble fraction was removed by filtration, and the filtrate was evaporated under reduced pressure. Ethanol was added to the concentrate to precipitate the material. The precipitate was filtered, dried in a desiccator, ground and passed through a 60 mesh sieve.

Hydrolysate by alkali (ALK) was prepared as shown in Fig. 1. RCB was treated with $17.5 \mathrm{w} / \mathrm{v \%}$ sodium hydroxide solution at $37^{\circ} \mathrm{C}$ for $16 \mathrm{~h}$ under nitrogen atmosphere, and hydrochloric acid was added to neutralize the solution. After filtration to remove insoluble matter, the solution was dialyzed for one night against flowing water and was evaporated under reduced pressure. Ethanol was added to the concentrate and the precipitate was filtered. The precipitate was dried in a desiccator, ground and passed through a 60 mesh sieve.

Determination of test substances Moisture and ash contents of ACD and ALK were determined by general methods. Crude protein was measured by the Kjeldahl method. The dietary fiber content was measured by the Prosky (AOAC) method (Ayano, 1995). Neutral sugar compositions were determined by gas-liquid chromatography (Hitachi 263-30) as alditol acetate (Ueno, 1970). Ferulic acid was analyzed as follows: ACD or ALK was treated in $6 \mathrm{ml}$ of 


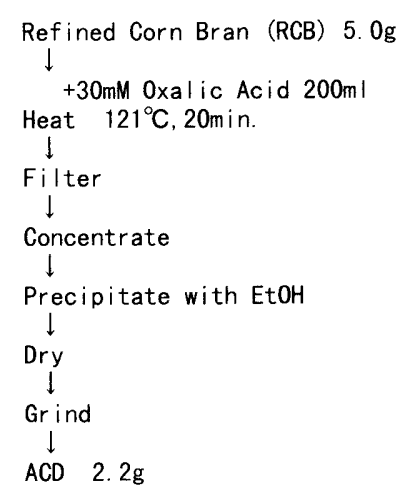

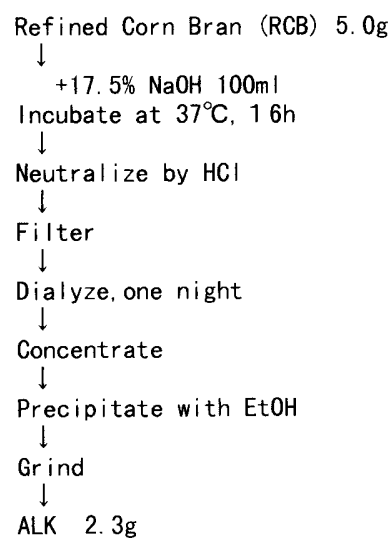

Fig. 1. Preparation of test substances.
Table 1. Composition of diets (\%).

\begin{tabular}{lccccc}
\hline Constituents & STD & CE & RCB & ACD & ALK \\
\hline Casein & 22 & 22 & 22 & 22 & 22 \\
Lard & 9 & 9 & 9 & 9 & 9 \\
Corn oil & 1 & 1 & 1 & 1 & 1 \\
Vitamin mixture $^{a)}$ & 1 & 1 & 1 & 1 & 1 \\
Salt mixture $^{a)}$ & 3.5 & 3.5 & 3.5 & 3.5 & 3.5 \\
Cholin bitartrate & 0.15 & 0.15 & 0.15 & 0.15 & 0.15 \\
Cholesterol & - & 1 & 1 & 1 & 1 \\
Sodium cholate & - & 0.25 & 0.25 & 0.25 & 0.25 \\
Sucrose & 58.35 & 58.1 & 58.1 & 58.1 & 58.1 \\
CE & 5 & 4 & 2 & 2 & 2 \\
RCB & - & - & 2 & - & - \\
ACD & - & - & - & 2 & - \\
ALK & - & - & - & - & 2 \\
\hline
\end{tabular}

${ }^{a)}$ Mineral and vitamin mixture were the same compositions as those recommended by American Institute of Nutrition (1976)

( $\mathrm{pH} 7.4$ ) was used as the solvent instead of $0.9 \% \mathrm{NaCl}$.

Xylanase activity Xylanase activities were determined by measuring the reducing sugar formed from incubation (MacKenzie et al. 1987) according to the Somogyi-Nelson method (Somogyi, 1952; Nelson, 1944). Xylose was used as the standard.

Arabinofuranosidase activity Arabinofuranosidase assays were carried out as described by MacKenzie et al. (1987), but $p$-nitrophenol release was measured at $400 \mathrm{~nm}$ instead of $410 \mathrm{~nm}$ (Shimadzu UV-1200 UV-VIS spectrophotometer) (Tamura et al., 1980).

Ferulic acid esterase activity Assays for ferulic acid esterase contained $1 \mathrm{mg}$ of ACD and enzyme at appropriate dilutions in $50 \mathrm{~mm}$ phosphate-buffered saline ( $\mathrm{pH}$ 7.4). The assay mixtures were incubated at $37^{\circ} \mathrm{C}$ and at the end of incubation, they were placed in a boiling water bath for 10 $\mathrm{min}$. After centrifugation at $3000 \mathrm{rpm}$ for $10 \mathrm{~min}$, the ferulic acid contents of the supernatant fractions were measured as described above for the determination of test substances.

Statistical analyses The significance of differences among the groups in CE, RCB, ACD and ALK were evaluated by Duncan's multiple-range test. These calculations were conducted using Yukms Statistical Library software (A.B.S., Inc., Tokyo).

\section{Results}

Components of $A C D$ and $A L K$ The components of ACD and ALK are shown in Table 2. Their major parts were polysaccharides. ACD contained $44.6 \%$ xylose, $8.6 \%$ arabinose and $4.1 \%$ ferulic acid. ALK contained $51.9 \%$ xylose and $38.0 \%$ arabinose, but ferulic acid was not detected.

Experiments on rats The body weight, food intake, liver weight and cecum weight in each experimental group are shown in Table 3 . All the groups were approximately equal in body weight gain, food intake and eviscerated carcass weight and liver weight. The cecum weight with the contents of ACD- and ALK-fed rats were heavier than those of CE-fed rats.

Table 4 shows the changes in cholesterol levels in serum. There were no significant differences among the groups, but ACD and ALK tended to repress the serum cholesterol levels during the feeding. There was no difference between CE- and contents were prepared according to the method Prizont et al. (1976), but $50 \mathrm{~mm}$ phosphate-buffered saline 
RCB-fed rats and ACD- and ALK-fed rats in HDL-cholesterol, triglyceride and liver cholesterol levels.

Enzymatic activities in cecal contents Xylanase activ-

Table 2. Components of test substances (\%)

\begin{tabular}{lrr}
\hline & ACD & ALK \\
\hline Moisture & 10.1 & 10.4 \\
Ash & 5.7 & 4.4 \\
Crude protein & ND & ND \\
Dietary fiber & 55.8 & 83.3 \\
Polysaccharide & & \\
$\quad$ Arabinose & 8.6 & 38.0 \\
Xylose & 44.6 & 51.9 \\
Mannose & 2.8 & 1.0 \\
Galactose & 1.9 & 5.9 \\
$\quad$ Glucose & 6.1 & 0.2 \\
\hline Ferulic acid & 4.1 & ND \\
\hline
\end{tabular}

ND means not detected.

Table 3. Effects of feeds on body weight, feed intake and organ weight.

\begin{tabular}{lcccc}
\hline & $\mathrm{CE}$ & $\mathrm{RCB}$ & $\mathrm{ACD}$ & $\mathrm{ALK}$ \\
\hline Initial body weight $(\mathrm{g})$ & $167 \pm 2^{\mathrm{a}}$ & $167 \pm 3^{\mathrm{a}}$ & $167 \pm 3^{\mathrm{a}}$ & $167 \pm 5^{\mathrm{a}}$ \\
Final body weight $(\mathrm{g})$ & $238 \pm 4^{\mathrm{a}}$ & $239 \pm 5^{\mathrm{a}}$ & $239 \pm 2^{\mathrm{a}}$ & $234 \pm 9^{\mathrm{a}}$ \\
Weight gain $(\mathrm{g})$ & $71 \pm 3^{\mathrm{a}}$ & $72 \pm 3^{\mathrm{a}}$ & $72 \pm 1^{\mathrm{a}}$ & $67 \pm 5^{\mathrm{a}}$ \\
Feed intake $(\mathrm{g})$ & $200 \pm 3^{\mathrm{a}}$ & $195 \pm 4^{\mathrm{a}}$ & $195 \pm 1^{\mathrm{a}}$ & $191 \pm 7^{\mathrm{a}}$ \\
Feed efficiency & $0.36 \pm 0.01^{\mathrm{a}}$ & $0.37 \pm 0.01^{\mathrm{a}}$ & $0.37 \pm 0.00^{\mathrm{a}}$ & $0.35 \pm 0.01^{\mathrm{a}}$ \\
Eviscerated carcass & $179 \pm 3^{\mathrm{a}}$ & $181 \pm 4^{\mathrm{a}}$ & $177 \pm 1^{\mathrm{a}}$ & $175 \pm 7^{\mathrm{a}}$ \\
$\quad$ & & & \\
$\quad$ weight $(\mathrm{g})$ & & & & \\
Carcass weight/Body & $76.0 \pm 1.1^{\mathrm{a}}$ & $75.7 \pm 0.4^{\mathrm{ab}}$ & $73.9 \pm 0.7^{\mathrm{b}}$ & $74.6 \pm 0.1^{\mathrm{ab}}$ \\
$\quad$ weight (\%) & & & & \\
Liver (g) & $11.1 \pm 0.3^{\mathrm{a}}$ & $11.4 \pm 0.4^{\mathrm{a}}$ & $1.2 \pm 0.2^{\mathrm{a}}$ & $11.9 \pm 0.6^{\mathrm{a}}$ \\
Cecum with contents $(\mathrm{g})$ & $2.0 \pm 0.2^{\mathrm{a}}$ & $2.1 \pm 0.1^{\mathrm{a}}$ & $3.8 \pm 0.3^{\mathrm{b}}$ & $3.2 \pm 0.5^{\mathrm{b}}$ \\
\hline
\end{tabular}

Values are mean \pm SE $(n=5)$.

Values in the same line without common superscript letter donate significant difference $(p<0.05)$.

${ }^{a}$ Weight gain/Feed intake

Table 4. Effects of feeds on serum lipids and liver cholesterol.

\begin{tabular}{|c|c|c|c|c|}
\hline & $\overline{\mathrm{CE}}$ & $\mathrm{RCB}$ & $\mathrm{ACD}$ & ALK \\
\hline $\begin{array}{l}\text { Ingested cholesterol } \\
(\mathrm{mg})^{a)}\end{array}$ & $1996 \pm 30$ & $1953 \pm 37$ & $1953 \pm 14$ & $1910 \pm 71$ \\
\hline \multicolumn{5}{|l|}{ Serum lipids: } \\
\hline \multicolumn{5}{|c|}{ Total cholesterol $(\mathrm{mg} / \mathrm{dl})$} \\
\hline 6 days on diet & $213.7 \pm 15.3$ & $200.8 \pm 17.6$ & $203.5 \pm 18.3$ & $196.0 \pm 8.4$ \\
\hline 10 days on diet & $233.4 \pm 13.5$ & $199.3 \pm 23.5$ & $189.6 \pm 24.2$ & $208.9 \pm 16.6$ \\
\hline 11 days (at sacrifice) & $195.1 \pm 15.6$ & $168.7 \pm 17.3$ & $161.7 \pm 33.7$ & $147.1 \pm 15.0$ \\
\hline $\begin{array}{l}\text { HDL-cholesterol } \\
(\mathrm{mg} / \mathrm{dl})\end{array}$ & $14.8 \pm 1.0$ & $17.5 \pm 2.6$ & $16.9 \pm 0.6$ & $21.0 \pm 2.0$ \\
\hline $\begin{array}{l}\text { Triglyceride } \\
(\mathrm{mg} / \mathrm{dl})\end{array}$ & $83.4 \pm 18.9$ & $96.9 \pm 18.0$ & $97.1 \pm 9.6$ & $94.1 \pm 12.8$ \\
\hline \multicolumn{5}{|l|}{ Liver cholesterol: } \\
\hline $\begin{array}{l}\text { Cholesterol } \\
\text { (mg/g of tissue) }\end{array}$ & $30.8 \pm 0.9$ & $30.0 \pm 1.7$ & $31.6 \pm 0.7$ & $31.0 \pm 0.8$ \\
\hline $\begin{array}{l}\text { Cholesterol } \\
\text { (mg/liver) }\end{array}$ & $339.5 \pm 3.7$ & $343.4 \pm 2.7$ & $354.3 \pm 8.7$ & $370.0 \pm 27.6$ \\
\hline $\begin{array}{l}\text { Apparent accumulation } \\
\text { ratio }^{b)}(\%)\end{array}$ & $17.6 \pm 1.1$ & $17.0 \pm 0.3$ & $18.1 \pm 0.5$ & $19.3 \pm 0.9$ \\
\hline
\end{tabular}

Values are mean $\pm \operatorname{SE}(n=5)$.

${ }^{a}$ Ingested total cholesterol during experimental period.

${ }^{b)}$ Apparent accumulation ratio of the liver cholesterol to ingested cholesterol. ities were determined by measuring the reducing sugar. Reducing sugar was observed in the cecum of ALK- and ACD-fed rats from the beginning of incubation and increased with incubation time. A small amount of reducing sugar was noted in the cecum of CE- and RCB-fed rats after 5-h incubation. Figure 2 shows liberated sugar after $16-\mathrm{h}$ incubation. There was much reducing sugar in the cecum of the ACD- and ALK-fed rats, but a small amount of sugar was detected in the cecum of the CE- and RCB-fed rats.

Arabinofuranosidase activities were determined by measuring the liberated $p$-nitrophenol. $p$-Nitrophenol was observed in the cecum of the ALK- and ACD-fed rats from the beginning of incubation and increased with incubation time. Figure 3 shows released $p$-nitrophenol after $20 \mathrm{~min}$ incubation. $p$-Nitrophenol in the cecum of the ALK-fed rats was more than in that of the ACD-fed rats. A small amount of $p$-nitrophenol was detected in the cecum of the CE- and RCB-fed rats.

Figures 4 and 5 show ferulic acid esterase activities. Figure

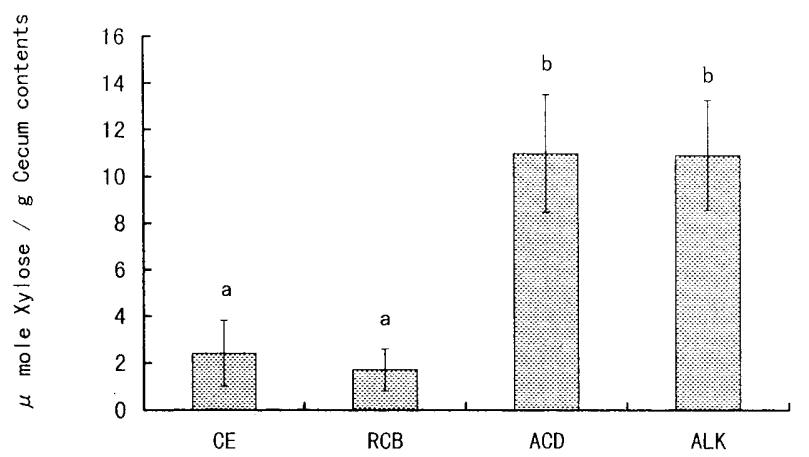

Fig. 2. Xylanase activities in the cecal contents of rats. Assays contained 0.5 $\mathrm{ml}$ of $0.5 \mathrm{w} / \mathrm{v} \%$ birchwood xylan (SIGMA) in $50 \mathrm{~mm}$ phosphate-buffered saline ( $\mathrm{pH} 7.4$ ) and enzyme at appropriate dilutions in a final volume of $2.5 \mathrm{ml}$. After incubation for $16 \mathrm{~h}$ at $37^{\circ} \mathrm{C}$, the assay mixture was placed in a boiling water bath for $10 \mathrm{~min}$ to terminate the reaction. This reaction mixture was centrifuged at $3000 \mathrm{rpm}$, and reducing sugar release was determined using $1 \mathrm{ml}$ of supernatant according to the Somogyi-Nelson method. $n=5$.

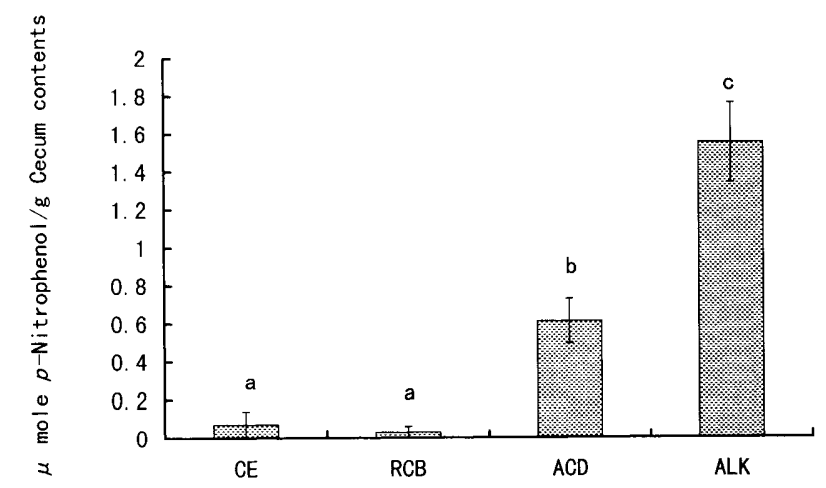

Fig. 3. Arabinofuranosidase activities in the cecal contents of rats. Assays contained $0.2 \mathrm{ml}$ of $0.05 \mathrm{w} / \mathrm{v} \% p$-nitrophenyl $\alpha$-L-arabinofuranoside in $50 \mathrm{~mm}$ phosphate-buffered saline $(\mathrm{pH}$ 7.4) and enzyme at appropriate dilutions and $\mathrm{Z}$ buffer in a final volume $2.0 \mathrm{ml}$. After incubation for $20 \mathrm{~min}$ at $28^{\circ} \mathrm{C}, 1 \mathrm{ml}$ of 1 $\mathrm{M}$ sodium carbonate was added and $p$-nitrophenol release was measured at 400 nm. $n=5$. 


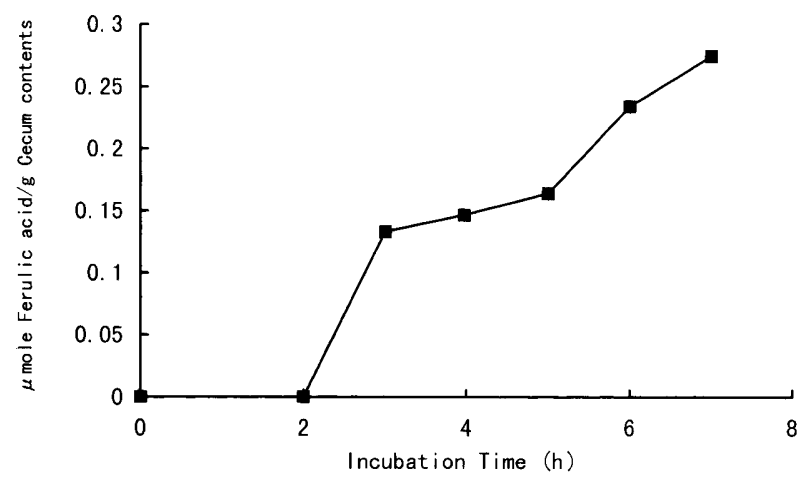

Fig. 4. Ferulic acid esterase activity in ACD-fed rat cecal content. Assays were performed as described in the text.

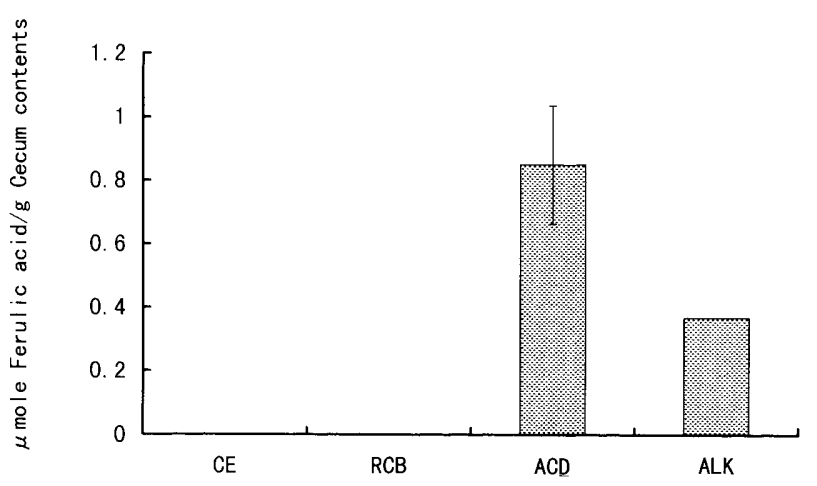

Fig. 5. Ferulic acid esterase activities in the cecal contents of rats. Assays were performed as described in the text. Incubation time was $16 \mathrm{~h} . n=3$.
4 shows the amount of ferulic acid liberated in the cecum of the ACD-fed rats. Up to $3 \mathrm{~h}$ from the beginning of incubation, no ferulic acid was detected, but after $3 \mathrm{~h}$, ferulic acid suddenly appeared and increased. Figure 5 shows liberated ferulic acid. Ferulic acid was observed in the cecum of the ACD- and ALK-fed rats and there was more in the cecum of the ACD-fed rats than in ALK. It was not detected in the cecum of the CE- and RCB-fed rats.

\section{Discussion}

Enzymatic activities in the ceca of rats fed on high cholesterol diets with differently processed dietary fibers from RCB were compared. One was hydrolyzed in acidic solution and another in alkaline solution. Most of the chemical components of ACD were polysaccharides: $44.6 \%$ xylose, $8.4 \%$ arabinose and $4.1 \%$ ferulic acid. ALK contained $51.9 \%$ xylose and $38.0 \%$ arabinose but no ferulic acid was detected. Kato (1992) analyzed the sugar components of plant cell walls using various kind of enzymes and reported that ferulic acid and glucuronic acid arabinoxylan ester, which had one ferulic acid ester per 50 sugar residues, was the main component when insoluble corn bran was treated with enzymes, but when treated with alkaline solution, ferulic acid was liberated. So in this experiment, the major component of ACD was suggested to be ferulic acid arabinoxylan ester in which arabinoxylan was partially esterified by ferulic acid, and ALK was arabinoxylan.

In enzymatic experiments, reducing sugar and p-nitrophenol were liberated gradually from the beginning of incubation, but ferulic acid was liberated after incubation was continued for $3 \mathrm{~h}$. This indicated that all enzymatic activities did not appear from the beginning of incubation. Xylanase activity, arabinofuranosidase activity and ferulic acid esterase activity appeared in the ceca of the ACD- and ALK-fed rats. However, these activities were not observed in the ceca of the CE- and RCB-fed rats (Figs. 2, 3 and 5). As mentioned previously, the main components of ACD and ALK were ferulic acid arabinoxylan ester and arabinoxylan. At first in ACD and ALK, xylanase was supposed to attack the xylose-xylose bond of the main chain where the arabinofuranose side chain was absent. At the same time, arabinofuranose of the side chain was considered to be hydrolyzed by arabinofuranosidase. ACD and ALK were assumed to be degraded and become lower molecular weight fragments in this way. Further in the case of ACD, ferulic acid esterase was thought to attack the arabinofuranose-ferulic acid ester bond of this lower molecular weight fragment. Mackenzie and Bilous (1988) studied the enzymes from the fungus Schizophyllum commune and reported that ferulic acid esterase acted optimally on wheat bran only in the presence of xylanase. In addition, they pointed out that the enhancement of ferulic acid esterase by xylanase was due to the size or inaccessibility of the material bearing the ferulic acid residue. In our experiments, xylanase, arabinofuranosidase and ferulic acid esterase were considered to act synergistically in a manner similar to that of the enzymes from the fungus. Because ACD and ALK were more refined than RCB, the components of RCB were more complex than ACD and ALK. Thus it might be more difficult for enzymes to approach and attack the RCB main chain and side chain.

Ferulic acid is well-known to have an antioxidant potential because it readily forms a resonance-stabilized phenoxy radical, and this radical has the ability to terminate free radical chain reactions (Graf, 1992). Soluble ferulic acid arabinoxylan ester, which was obtained from RCB hydrolysis by acids or enzymes, showed antioxidative activities against the autoxidation of linoleic acid and lipid peroxdation of rat liver microsomal system induced by $\mathrm{CCl}_{4}$ in vitro (Ohta et al., 1994). When a rat feeds on ACD, ferulic acid is isolated in the cecum. If ACD itself and the isolated ferulic acid would be absorbed in the cecum or the large intestine, they are expected to work as antioxidants in the body.

Hemicellulose which was isolated from corn bran had significant effects on preventing the elevation of serum and liver cholesterol levels of rats compared with CE (Takeuchi et al. 1991). Hemicellulose isolated from rice bran, whose main component was arabinoxylan, was fermented by bacteria that arose from men, especially by Bifidobacterium. When the rats ate this hemicellulose, the number of Bifidobacterium increased, the $\mathrm{pH}$ became lower and organic acids, particularly acetic acid, increased in cecum (Aoe et al., 1988). In the present study, the cecal contents of the rats fed on ACD and ALK were supposed to change similarly to those of the rats fed on hemicellulose isolated from rice bran, though 
changes in bacteria number, flora species and other enzymatic activities of bacteria were not clarified in these experiments. They should be elucidated. It is said that soluble dietary fiber has more physiological activities than the insoluble fiber. In fact, serum cholesterol level was suppressed more by soluble ACD and ALK than RCB. Insoluble CE did not have such an effect.

In these days, dietary fiber intake is decreasing in spite of its important physiological functions. The recommended daily dietary fiber intake is $20 \mathrm{~g}$. The addition of cereal bran extract to diets is one effective way of taking dietary fiber. Thus ACD and ALK are considered more effective than RCB itself. At that time, it is interesting that soluble dietary fibers from $\mathrm{RCB}$ by different processes showed different properties which were caused by ferulic acid.

\section{References}

Anderson, J.W. and Chen, W.J.L. (1979). Plant fiber. Carbohydrate and lipid metabolism. Am. J. Clin. Nutr., 32, 346-363.

Aoe, S., Ohta, F. and Ayano, Y. (1988). Effect of water-soluble dietary fiber on intestinal microflora in rats. Nippon Eiyo Syokuryo Gakkaishi, 41, 203-211 (in Japanese).

Ayano, Y. (1992). Dietary fiber in cereals: Nutrition and physiological aspect. Nippon Eiyo Shokuryo Gakkaishi, 45, 209-219 (in Japanese).

Ayano, Y. (1995). "Dietary Fiber," ed. by S. Innami and S. Kiriyama. Daiichi-Shuppan, Tokyo, Chapter 3 (in Japanese).

Brillouet, J.M., Joseleau, J.P., Utille, J.P. and Lelievre, D. (1982). Isolation, purification and characterization of a complex heteroxylan from industrial wheat bran. J. Agric. Food Chem., 30, 488-495.

Chen, W.J.L., Anderson, J.W. and Jennings, D. (1984). Propionate may mediate hypocholesterolemic effects of certain soluble plant fibers in cholesterol-fed rats. Proc. Soc. Exp. Biol. Med., 175, 215 218.

Ebihara, K. and Kiriyama, S. (1990). Physico-chemical property and physiological function of dietary fiber. Nippon Shokuhin Kogyo Gakkaishi, 37, 916-933 (in Japanese).

Graf, E. (1992). Antioxidant potential of ferulic acid. Free Radical Biol. Med., 13, 435-448.

Ikegami, S. and Innami, S. (1995). "Dietary Fiber," ed. by S. Innami and S. Kirihara. Daiichi-Shuppan, Tokyo, Chapter 7 (in Japanese).

Kamisaka, S., Takeda, S. and Shibata, K. (1990). Diferulic and ferulic acid in the cell wall of Avena coleoptiles-Their relationships to mechanical properties of the cell wall. Phsiol. Plant., 78, 1-7.

Kato, Y. (1992). Enzymatic dissociation of plant cell wall polysaccharides. Nippon Jozogakkaishi, 87, 107-115 (in Japanese).

Kirby, R.W., Anderson, J.W., Sieling, B., Rees, E.D., Chen, W.J.L., Miller, R.E. and Kay, R.M. (1981). Oat-bran intake selectively lowers serum low-density lipoprotein cholesterol concentrations of hypercholesterolemic men. Am. J. Clin. Nutr., 34, 824-829.

MacKenzie, C.R., Bilous, D., Schneider, H. and Johnson, K.G. (1987) Induction of cellulolytic and xylanolytic enzyme systems in Streptomyces spp. Appl. Environ. Microbiol., 53, 2835-2839.

MacKenzie, C.R. and Bilous. D. (1988). Ferulic acid esterase activity from Schizophyllum commune. Appl. Environ. Microbiol., 54, 11701173.

Nelson, N. (1944). A photometric adaptation of the Somogyi method for the determination of glucose. J. Biol. Chem., 153, 375-380

Nomani, M.Z.A., Fashandi, E.F., Davis, G.K. and Bradac, C.J. (1979). Influence of dietary fiber on the growth and protein metabolism of the rat. J. Food Sci., 44, 745-751.

Ohta, T., Yamasaki, S., Egashira, Y. and Sanada, H. (1994). Antioxidative activity of corn bran hemicellulose fragments. J. Agri. Food Chem., 42, 653-656.

Prizont, R., Konigsberg, N. and Aminoff, D. (1976). Glycosidase activity in the rat cecal content. Gastroenterology, 70, 928.

Shiba, K., Ijitsu, T., Hara, H. and Okada, K. (1992). Preparation and characterization of water-soluble hemicellulose (arabinoxylan) from wheat bran. J. Jpn. Soc. Food Sci. Technol, 39, 1147-1155.

Shibuya, N. (1984). Phenolic acids and their carbohydrate esters in rice endosperm cell wall. Phytochemistry, 23, 2233-2237.

Somogyi, M. (1952). Notes on sugar determination. J. Biol. Chem., 195, 19-23.

Tamura, G., Gold, C., Ferro-Luzzi, A. and Ames, B.N. (1980). Fecalase: A model for activation of dietary glycosides to mutagens by intestinal flora. Proc. Natl. Acad. Sci. USA, 77, 4961-4965.

Takeuchi, M., Sugawara, M., Takasyo, T., Egashira, Y., Sanada, H. and Ayano, Y. (1991). Development of corn dietary fiber materials with physiological functions. Nippon Shokuhin Kogyo Gakkaishi, 38, 981-989 (in Japanese).

Ueno, T. (1970). Determination of sugars by gas chromatography. Kagaku to Seibutu, 8, 114-121 (in Japanese). 